\title{
Women's experiences
}

with ovarian cancer:

Reflections on being diagnosed

\author{
By Margaret Fitch, Karen Deane, \\ Doris Howell, and Ross E. Gray
}

\section{Abstract}

The purpose of this qualitative study was to describe the perspectives of women living with ovarian cancer about their experiences with diagnosis, treatment, and follow-up care. A convenience sample of 18 women was interviewed using an openended interview guide. This paper will focus on their perspectives during the peri-diagnostic period.

Most of the women in this study experienced changes in their bodies - bloating, weight gain around their middles, indigestion, bowel changes, and abdominal pain. The vagueness of the symptoms and lack of awareness by the women and, in the women's opinion, health care professionals caused delays in diagnosis and initial investigations of other body systems. The symptoms were often dismissed by the women as being related to normal body changes such as childbirth, menopause, or stress responses. It was often not until the women's symptoms became severe or included pain that referrals were made to relevant specialists. At this point, many of the women were physically and emotionally spent, leaving them vulnerable and in a weakened state for confronting the diagnosis and coping with the difficult course of treatment. Clearly, the subtle, nebulous nature of the symptoms confounded the diagnosis of ovarian cancer for these women, resulting in patient delays and physician delays.

Implications emerge from this work for better screening tests as well as public, patient, and health professional education about the warning signs and symptoms of ovarian cancer.

Ovarian cancer is the leading cause of death from reproductive disorders (Clark \& Matassarin, 1993). In 2000, there were 2,500 women diagnosed with ovarian cancer and 1,500 who died from their disease (NCIC, 2000). Seventy-five per cent of women who have ovarian cancer are diagnosed with advanced (stage III or IV) disease (Young, 1995) and, as with other cancers, prognosis is linked to the stage of disease and gradient of tumour at diagnosis.

Ovarian cancer has been described as a silent predator of unsuspecting women. Its vague symptoms and the paucity of empirical research about the disease confound its diagnosis and management. Late diagnosis has limited the understanding of the course of the disease. Ovarian cancer and its treatment also may have considerable effect on a woman and her family. It often has a prolonged and variable course characterized by initial response to antineoplastic therapies, followed by relapse and progression of disease.

At present, little is known about the experiences of women who are living with ovarian cancer. Existing research tends to focus on describing symptoms (Montazeri, McEwen, \& Gillis, 1996; Portenoy, Kornblith et al., 1994), including psychosocial distress (Kornblith et al., 1995), or measuring quality of life with standardized scales (Guidozzi, 1993; Roberts, Rossetti, Cone, \& Cavanagh, 1992;
Zacharias, Gilag, \& Foxall, 1994) and standardized interviews or surveys (Dawson, 1993; Fitch, Gray, DePetrillo, Franssen, \& Howell, 1999; Powel, 1998). These studies have shown relatively consistent findings: marked anxiety and depression have been observed in many women; sexuality is often negatively influenced; social functioning is impaired, especially as it relates to the ability to work; and physical functioning and disease progression are often predictive of changes in quality of life. Symptoms such as fatigue, pain, and psychological distress are most prevalent in this population (Portenoy, Thaler et al., 1994). Additionally, studies often focus on gynecologic cancer, but may not report findings specific to ovarian cancer patients (Cain et al., 1983; Roberts et al.).

Few studies have utilized qualitative approaches to describe the viewpoints of women about living with ovarian cancer (Ersek, Ferrell, Dow \& Melancon, 1997). Allchin-Petardi (1998) used a sample of women with ovarian cancer to test Parse's theory of human becoming. Interviews with eight women focused on overcoming hardship and uncovered three core concepts: deliberately persisting, significant engagements, and shifting life patterns. Payne (1990) utilized open-ended interviews to explore ovarian cancer patients' coping with chemotherapy. Four predominant coping styles emerged from her analysis: think positive/fighter, acceptance, fearfulness, and hopelessness.

The purpose of this study was to describe the experiences of women living with ovarian cancer. It was anticipated that by understanding their viewpoints regarding their experiences during diagnosis, treatment, and follow-up care, insight could be gained for improvements in care delivery, as well as identifying ideas for future research.

\section{Background on ovarian cancer}

The majority of ovarian cancers are epithelial tumours, although others are adenocarcinomas or evolve from germ or stromal cells. Symptoms of ovarian cancer include abdominal distention, urinary frequency and urgency, pleural effusion, malnutrition, and pain from pressure caused by tumour growth. The patient may also complain of effects of urinary or bowel obstruction, constipation, ascites with dyspnea, and eventually generalized, severe pain. The appearance of symptoms is usually indicative of pressure on surrounding

Margaret Fitch, RN, PhD, is Head of Oncology Nursing and Supportive Care at Toronto-Sunnybrook Regional Cancer Centre and one of the Co-directors of the Toronto-Sunnybrook Psychosocial and Behavioral Research Unit in Toronto, Ontario. Karen Deane, $R N, M N$, is a Research Assistant at TorontoSunnybrook Psychosocial and Behavioral Research Unit, Toronto. Doris Howell, RN, MScN, PhD(c), is an Independent Consultant in Oncology/Palliative Care in Toronto.

Ross E. Gray, PhD, is a Psychologist, and one of the Co-directors of the Toronto-Sunnybrook Psychosocial and Behavioral Research Unit in Toronto. 
organs and metastasis to fallopian tubes, uterus, and ligaments. By the time symptoms appear, disease is likely already widespread. Tumour cells have travelled to distant organs via pelvic blood vessels, resulting in lymph and blood involvement and peritoneal seeding.

The risk factors associated with ovarian cancer are age over 40 years; family history; nulliparity; infertility; history of heavy menstrual bleeding; dysmenorrhea; North American or Northern European ethnicity; health history of endometrial, colon, or breast cancer; and hereditary ovarian cancer syndromes (Clark \& Matassarin, 1993; Lee, 2000). Pregnancy, breast-feeding, tubal ligation, hysterectomy, and oral contraceptive use appear to lower a woman's risk of developing ovarian cancer. Other studies have tried, albeit unsuccessfully, to determine a relationship between ovarian cancer with diet and/or perineal talc exposure (Health Canada, 1999).

Diagnostic tests for ovarian cancer include bimanual pelvic examination, transvaginal ultrasound, and CA-125 (blood sample) testing. Combining these three investigations improves the chances of finding an early stage ovarian cancer in women at risk. However, lack of evidence of test effectiveness makes each of these strategies problematic and the need for evidence-based guidelines in this area has been identified (Gray, Chart, Carroll, Fitch, \& Cloutier-Fisher, 1999).

Treatment for ovarian cancer usually includes surgery, chemotherapy, and/or radiation. A total abdominal hysterectomy, bilateral salpingo-oophrectomy with omenectomy, and debulking of the tumour are done initially to stage the tumour, confirm the diagnosis, and remove as much of the tumour as possible. Radiation treatments and various combinations of chemotherapy agents are given in an attempt to diminish symptoms, delay recurrence, and improve survival rates. To date, hormone treatment and immunotherapy offer little benefit over standard chemotherapy regimes. A combination of platinum chemotherapy consisting of cisplatin and carboplatin and/or taxol is the first line chemotherapy of choice in Canada. Although this standard treatment for chemotherapy provides a 70 to $80 \%$ response rate, long-term survival rates remain poor (Balat et al., 1996).

\section{Purpose of the study}

The purpose of the study was to describe the experiences of women with ovarian cancer during their diagnostic, treatment, and follow-up care periods. The interview approach allowed the women to talk about the topics that were of importance to them.

\section{Methods}

The study sample consisted of 18 women who were interviewed regarding their experiences with ovarian cancer. Women were identified through nurses and gynecologic oncologists in two major cancer centres. The criteria for participation included: 1) ovarian cancer diagnosis, 2) able to speak English, and 3) able to talk about their experiences. The nurses and oncologists invited the women to participate in the interview. An invitation to participate was also extended in a letter to the local ovarian cancer support group. Potential participants were asked to give permission for the nurse researcher to receive their names and telephone numbers. The research nurse called interested women to explain the purpose of the study in detail and to schedule an interview at a convenient time. Women were informed that neither participation in the study nor refusal to participate would in any way affect their care. Information about the ethical issues, including confidentiality and the reporting of aggregated data, was given before a verbal consent was obtained over the telephone from each woman. The study was approved by the ethics committee of Sunnybrook and Women's College Health Sciences Centre.
The interviews, lasting about an hour, were conducted over the telephone and audiotaped. Telephone interviews were used because of convenience for the participants and study budget restrictions on travel for the interviewer. The individual who conducted all the interviews was a Master's-prepared nurse with a high level of skill in this type of work (KD).

A semi-structured interview guide was used to conduct the interviews. The questions served as a stimulus to help the woman tell about her experiences during diagnosis, treatment, and followup care. The participants were asked to talk about what had happened to them regarding their ovarian cancer from the time they were first aware something was different about their bodies to the time of the interview. The interviewer listened as the woman shared her experiences, and also probed for the following topics if the participant did not volunteer the information: making therapy choices, obtaining information, involvement in decision-making, living with the impact of the illness, changes in lifestyle, and obtaining supportive care services. These probes were developed on the basis of issues that had been previously described in the literature as key issues for breast cancer patients (Gray, Fitch et al., 1998; Gray, Greenberg et al., 1998). Demographic information (i.e., age, marital status, length of time since diagnosis, number of children, education, and current work status) was gathered to provide a description of the participants.

Interview data were transcribed verbatim and all 18 interviews were read by three of the authors (MF, KD, DH). Working together and comparing impressions of each woman's story, these three authors designed a coding category scheme for the data. This scheme facilitated the organization of the data into content categories. Data were coded by one author (KD) according to the categories developed by the three authors. The overall category scheme did not change during the course of the coding. Finally, the data in each content category were reviewed by the authors and themes were developed to reflect the broad ideas shared by the women.

During the analysis, it became apparent that there was a wealth of information contained in the interviews. To do justice to the data, the team decided to write several articles to share the findings of this work. This article will focus on the perspectives women shared about the peridiagnostic period. Subsequent articles by the authors will discuss findings from this study concerning women's experiences undergoing treatment, confronting the emotional impact of this disease, and dealing with recurrence.

\section{Findings}

Two themes related to the peridiagnostic interval emerged from the findings. The two themes are the focus of this article and are described in detail. Quotes have been used to illustrate the perspectives women have shared. Pseudonyms are used in the text.

\section{Sample}

Eighteen women were interviewed about their experience with ovarian cancer. The mean age for the sample was 53.2 years (range of 35 to 73 ). The mode for the time since diagnosis was five months. More than half of the sample $(n=12)$ had been diagnosed in the 12 months prior to the interview. The remaining women were between 13 months and 12 years postdiagnosis.

Twelve women in the sample were married and six were without a partner, being either single, separated, divorced, or widowed. Six women in the sample did not have any children, while 12 had between one and four children. Two women completed primary school education, six completed secondary school, seven attended university, and three attained college 
diplomas. Eight women did not work outside the home by choice or because of retirement at the time of the interview. Six women were on long-term disability from their jobs. Four women had returned to work on a part-time or full-time basis after their diagnosis and initial course of treatment.

\section{Theme one: Getting the definitive diagnosis
was a long and winding path}

The women in this study often described the process of symptom assessment as a long and winding path before a definitive diagnosis was made. The vague symptoms of ovarian cancer were frequently unrecognized as warning signs by the women themselves and by health professionals. The women confused symptoms and physical complaints with normal body changes they thought were related to childbearing or menopause, or dismissed the symptoms as being caused by other stressful situations in the woman's life. In any case, women did not think the symptoms were important enough to pursue.

Looking back I would say, yes, there were symptoms there. But had I realized that this could be a warning of a cancer I certainly would have done something about it. But I just thought they were annoyances or things that changed as a result of having children or things that were changing as a result of aging...yeah, I had urinary frequency and urgency. ...I would think it was as a result of the birth. [Sally]

I was having problems with my tummy and this was prior to my daughter's getting married, so we had assumed that it was irritable bowel syndrome. Related to the stress of the wedding. And also at that time my husband was unemployed. He was let go from his job and I was let go from my job...it all happened at the same time. [Betty]

...for at least six months I had just steadily gained weight and... my abdomen just seemed to keep bulging, you know. And I felt no pain. ...but I just thought well you know I'm about 50 years of age and, you know, it's just something that comes along with that age....plus, you know, my side of the family, you know, are a little on the stout side ...I didn't really pay any attention to it because I had, you know, I had no pain. ...I didn't really suspect anything until... I just started feeling a little bit of pain. ...also I guess (I was) approaching menopause, you know, my cycle wasn't real normal. [Ann]

At the time of the interview, women expressed regret at not realizing what the symptoms could mean. For most of them, cancer was not initially considered to be a possible explanation of their symptoms or the changes they were experiencing.

If I had connected in any way the cancer, I wouldn't let my tummy get so big. [Jennie]

But there was really nothing to alert me and I had never read about ovarian cancer. And I mean, now, as I look back on it, if I had read even the first paragraph that's in most articles about ovarian cancer I'd have been suspicious. [Jane]

...an early sign, the problem passing urine. And I guess it was just because of pressure... but when I told him (family physician) about that he didn't seem to know that it meant anything at all and I guess it did...I kept telling myself that... it was just gas. I thought, you know, I couldn't have cancer because I felt all right and I could still do everything. [Joan] In this sample, five women did not have symptoms. Their ovarian cancer was diagnosed through incidental testing for issues such as fertility or after elective surgery for medical conditions. The other 13 women experienced physical symptoms including bloating, gastrointestinal symptoms, fatigue, sexual problems, and eventually pain. However, when they sought assistance, most of these symptoms were attributed to gastrointestinal problems or menopause and were not generally investigated until the symptom of pain was experienced.

Now I know. But at that point I'd always been healthy. And I just thought that if I was constipated, I wasn't eating right. And then it would go from constipation to diarrhea, which is one of the things that happens I've since learned, and I would just think well it's something I've eaten. I never thought to tell that to the doctor and he didn't ask. [Pam]

...now looking back there were questions that I wasn't asked. Well, I was in the office because I was 52 years of age, I didn't look as if I was going into menopause, I was having very heavy painful periods and something wasn't right. [Jane]

And I didn't have bloating; I didn't have pain; I didn't have constipation; just a little nagging pain. ...The interesting thing was I'd had an ultrasound earlier and it was normal... But then my husband got sick and I was not thinking about those things then. Not thinking about the nagging pain, you know, I had to focus on him. So three months after he died, when I got the pain, it came back. Then I thought now I can focus on myself.... [Diane]

The symptoms women experienced were sometimes thought to be indicative of diseases from abroad. Women who travelled found their recent trips were the focus for the early diagnostic investigations. Others were questioned about foreign infection routes.

I started to have stomach problems, stomach cramps and diarrhea.... And I thought it was just living (abroad) - food and those things - whatever. ...And first of all I was diagnosed as having [infection] genitally and vaginally, and got a bunch of antibiotics for that. And still the symptoms seemed to persist....And the stomach stuff sort of came and went and I didn't think anything of it and I don't know now whether it was - it was simply dietary or it really was cancer at that point. [Joan]

I started to develop fever. ...I would go to bed and I was fine and all of a sudden I would have the fever. And I would feel faint. I would feel short of breath and I would feel very, very weak. ...(doctor) sent me to all kinds of tests and then she says that, "Have you been to a tropical place? ...because you could have a virus and, you know, it would be undetected." [Judy]

Some of the women presented with severe, obstructive symptoms that required immediate investigation or emergency treatment. These women, for the most part, had not attended to changes in their bodies earlier. Most were not cognizant of the importance of symptoms or the risks for ovarian cancer.

...I couldn't walk, because the pain was so bad. ...someone came and picked me up and I went home and I just lay down. And I waited a couple of days and I went to my doctor cause I was going for blood tests that day because I hadn't been feeling well. I just felt like really, really tired, all the time. ...when I lay down on the bed he (doctor) noticed something... they had me in for surgery the following morning. It didn't even take 24 hours to get me in. [Holly]

I guess I didn't think cancer... I thought maybe a cyst... I wasn't one of these people that you know just always have a fear that they're going to have cancer.... (I) didn't think that. He (doctor) waited for the $x$-ray results and then he just said, "Well, you know it's looking pretty serious. You probably should go right over to the hospital." ...I was concerned... I was to have both, an 
abdominal ultrasound and a pelvic (ultrasound) ...they wanted me to go right on to a CAT scan....And then you know within a short while... it was a different doctor, and I don't know who she was....And she was left to break the news to us that, you know, it was probably $95 \%$ sure that it was cancer. [Ann]

Other women lived through painful and frightening progression of their disease before medical practitioners were able to ascertain the cause of their symptoms. They often saw various specialists who focused on the specific area of their professional expertise and did not seem to attend to the real cause of the symptoms. The women felt frustrated enduring such severe symptoms with no resolution.

I started to bloat up... my stomach and there was swelling and (I was) constipated. And I'm not used to that; I'm pretty normal. And so I took prunes and different things, you know, just trying your own remedies and I was really uncomfortable. I just didn't have a waist anymore, you know, it was all bloated. [Maria]

So at this point... I was not eating because everything made me feel sick. I bought pablum but even that didn't work. I wasn't sleeping because I was in pain and so I was just staying up and trying to get in the bathtub to relieve this pain. And keep going back to the doctor and... a gastrointestinal specialist at that point, saying all that bloating is just gas. [Susan]

My tummy was getting so big I couldn't eat. I had the appetite it's just that my tummy didn't have any space at all. So, even a sip of water wouldn't go down. It's getting so big it's annoying. And I went to different doctors, but they said "Oh, you have a gastro problem. ...you have gases in your stomach like, some stomach problem. And you have a hernia in your stomach area". But they never addressed my big tummy. [Jennie]

As women became more ill, they were increasingly vulnerable to serious health implications. Many women sought help but felt that their complaints were not acknowledged or respected, either by the health care professionals or family members. Concern mounted as women grew more baffled about their continuing health problems.

I had the symptoms for years, like for at least two years. I complained to my GP... sexual intercourse was painful. I complained to her about being tired all the time, having no energy. ...Why am I sick all the time? ...Finally the pain got so bad that I found a new GP and she sent me for all the tests; didn't tell me what she suspected....Sent me for all the tests and they knew what they were looking... to see if it was in my bowels. And they never told me that... they treat you like a child. [Gail]

...because the doctor can't find something wrong with you. And it's even more painful when people, they don't believe you. They think you're making it up....And besides I had pains in my, you know, in my tummy, coming and going, here and there. And he said... well, he didn't believe me. In other words I don't know, maybe he thought I was making it up. And then (two months later) he said, "Oh well, I'll send you to an ultrasound." And then the ultrasound stated that they found a cyst behind, no, in the uterus. [Judy]

So, when I went to my family doctor, he said, "It's not a tumour there." Because my tummy was so big, it's like I am four to five months pregnant... "You have a little tummy growing." ...I thought to myself it's a... problem area. It grows bigger and bigger and it grows over for, I guess for a period of two years to 18 months. It's alarming. It never gets to an alarming stage like that (before). And I can't eat because the food and the water fluid never go down. [Jennie]

Even when patients had routine check-ups and appropriate medical investigations, the ovarian cancer was frequently not discovered early. Women expressed confusion about the symptoms and abrupt changes to their bodies and lifestyles.

...I'm a very active person, never had any sickness or disease in my life, always had regular check-ups, had two children and was very, very active. And in early September I kind of didn't feel my usual self. I was working part-time, two days a week. ...I had a little stomach cramps. And I thought, "Oh well, I don't know, maybe I better go see my GP." ...he did a Pap test and he said, "I don't know, maybe you should see a gynecologist," whom I've never had at all... And the following week... I really felt sick, no energy, couldn't curl, couldn't do anything; went back to my GP. He said, "I think I'll send you for an ultrasound" and at that time my appointment was moved up too, with the gynecologist. ...Had an ultrasound on the Wednesday didn't take. Went back on Friday for an ultrasound. And practically before I got home my GP phoned and said you better cancel your trip(s). [Dawn]

A previous history with a cancer experience occasionally served to urge health professionals to investigate the women's complaints more thoroughly. Also, other health problems and astute technicians sometimes helped shepherd physicians towards the ovarian cancer diagnosis.

I had sort of symptoms for a few months, which were sort of standard like flu symptoms, and had a fullness in the stomach. And, because I had been diagnosed with a breast cancer in 1993, my GP saw the little red flag go up. I went in for a pelvic CAT scan and I went in for a pelvic ultrasound, which turned into a vaginal ultrasound, which the latter, by the way, found the cysts that they felt were malignant. ...Phenomenal technician, who didn't see a thing in the pelvic ultrasound... But, it was because of that technician, asking for the vaginal ultrasound, that's when the results came up that I had the cysts on both ovaries. [Ellen]

I had no symptoms at all. I was originally in the hospital. I had a valve replaced... and had an ultrasound... And while they were doing the ultrasound... the technician did the ultrasound a little lower than she had to. And that's how she found the cancer. So it was by accident. Now why it wasn't found with all the other tests I don't know. [Frances]

Some women felt intuitively that something dire was wrong with their bodies. Unfortunately, their intuition was validated and their fears realized when the ovarian cancer diagnosis was made.

It was funny, I had this terrible premonition that it was something because they made an appointment... and they sent me for an ultrasound. And I remember... calling them and saying... "If you get a cancellation I can come." ...And, you know, two days later they said, "We've had two cancellations. Can you come in thirty minutes?" And I was up there like a shot... I just felt that it had to be done although the thought of ovarian cancer never entered my head. I don't know what I thought. I just knew there was something wrong. [Diane]

...(diagnosis) wasn't quite as much a shock as you might have thought because the couple of weeks prior, actually a month prior to going into the hospital, I began to feel that there was perhaps something more wrong than what I had thought, like I had fibroids which I did. But I seemed to be getting more and more distressing symptoms. [Jane]

During the course of their time with ovarian cancer, the women learned to trust their own awareness and perceptivity 
about their bodies. For some, that learning was acute at the time of diagnosis, while for others it was more pointed after treatment had finished, and emerged as they thought back over their experience. Many indicated a desire to pass this lesson on to other women.

Don't dismiss something (symptom) and don't let your doctor tell you that just because you're a woman you're going to experience these things. Everything is not to be put down to menopause or PMS or anything else. [Jane]

\section{Theme two:}

\section{Communication with health care professionals was confusing and difficult}

Looking back, the women felt that they had little access to information during the diagnostic interval or at the time of the initial diagnosis. Information about ovarian cancer and its risks was not readily available.

Communication with health professionals during the diagnostic interval was at times confusing and difficult, especially for women experiencing symptoms without a definitive diagnosis. Women were uncomfortable physically, and emotionally they were filled with anxiety about their health concerns.

...they (doctors) still didn't tell me anything but the day before the surgery a doctor, a woman doctor... she sat down on my bed and said, "Well, you probably have cancer and this is what they're going to do and they're going to take out everything." And I said "everything!" ... I said "even my cervix?" And she said, "Oh yeah, they'll take out everything." And I said to her "well, won't I get all loose and won't everything fall down?" And she said, "Oh no, they'll just bolt the ligaments together. And you'll lose your sex drive and you'll dry up." And this is a woman doctor! [Gail]

The women in the study were frustrated when health professionals did not always listen to the women's intuitive concerns and instead remained focused on one specific body system.

At some point actually I can recall talking to my doctor on the phone and saying, "Could this be something to do with my ovaries?" And her saying, "No, we're definitely in the right system, you know, the symptoms are all gastrointestinal." And I have absolutely no idea why I thought that! You know, I didn't even know where my ovaries were, but it just came out of my mouth. [Susan]

They expressed disappointment with health professionals' behaviours in that they felt some of the health professionals were hesitant and not forthright with information about the diagnosis.

And the surgeon kept coming and saying, "Well, I'll tell you in a few days when you come out of the anesthetic." But then my family doctor came in and I said, "Look... I want to know," and she told me. She said, "Yes, they found cancer." [Diane]

I was still in the hospital and he (doctor) came in the next morning to tell me that... we would talk in six weeks. I don't think he wanted to really give me any information at that time. Cause they wanted to look over... the biopsy they had done. But he already knew that it was cancer. ... I asked the questions probably that he (doctor) didn't want asked. [Mary]

The health professionals' attitude and behaviours were important aspects to the quality of the communication exchange between patient and physician. Women wanted answers to their various questions and a respectful approach to their concerns.
Then I went and had an appointment with the doctor that did the surgery. And he explained what he did and even he drew a diagram. The interesting thing was when he told me that he had to scrape the larger ovarian cyst off the pelvic wall. And when they did washings, it was infested with cancer cells. I shed a few tears and you know what he said? "I don't like people crying in my office." ...I remember coming outside sitting waiting for a cab, sitting on a bench crying. [Diane]

My pain is sometime in one place, sometime it moves. It's like almost like a snake that moves. It isn't there all the time. I don't know how they interpret it, you know... I have the pain and not them. So I told him that and he said, "Well, I don't want to hear about this unless it's there all the time." [Judy]

...as soon as I came out of the surgery I woke up and there was two nurses turning me... And I just said, "What did they find?" ...the two nurses looked at each other and didn't look at me and they just said, "The doctor will tell you." ...I knew then it wasn't just a hysterectomy and it wasn't a harmless cesarean [ovarian] cyst. The nurses looked very uncomfortable. ...you recognize it. You always watch the body language of nurses and doctors. ...They were only two young nurses, you know, and I guess they didn't have their poker faces. [Diane]

Direct communication about the cancer diagnosis was sometimes delayed or presented to other members of the patient's immediate family before the patient herself. The diagnosis frequently validated the patients' symptoms and concerns about their health, as well as brought an end to continuous investigations and progressing discomfort. It also gave a sense of hope to the women that the cause of their symptoms could be relieved and treated.

So eventually they did a laparoscopy and found some kind of nodules around my abdominal cavity. And they didn't know whether it was, at that point, tuberculosis or something else. And they didn't tell me what the something else was and cancer never even crossed my mind. ... a few days later, the nurse said, "Oh your doctor has called and she wants to meet with you and your husband in this room," in a separate room....And it turns out my husband called and found out what the other thing possibly was, so he sort of was a bit in the know. So we went into this room and waited for the doctor. And she came in and said, "It's carcinoma and it's metastasized," and that's when I found out what it was. And I was actually relieved to find out that it was something, you know... Finally someone was saying, "Yeah there's really something wrong with you." It's not, you know, this irritable bowel that I feel like, "Oh, yeah we don't know what's wrong, it might be in your head; we'll tell you it's irritable bowel." ...[now]I knew what I was dealing with. Yeah, that I could, that we could now have some treatment or whatever. [Susan]

These women often had not even considered cancer as a possible cause of their symptoms. When they were diagnosed, they sometimes had to clarify with the physicians that their diagnosis was in fact cancer. The news of an ovarian cancer diagnosis elicited overwhelming emotions for the women and their families.

She (doctor) managed to get me an appointment with a gynecologist. ...I went into his office and... he examined me. In no time at all he felt something; didn't tell me what he felt... He said... it was probably ovarian cancer. I was shocked! Burst into tears. ...he drew a diagram - I still have it - what he would do and "Did I want to seek another opinion?" [Gail] 
I had started to cry. And I cried so badly and the doctor (gynecologist) never, never mentioned anything such as cancer. But, she knows, well, cause my tummy was so big. But, I was so naive and she didn't want to scare me cause I'm crying enough. And, she said, "Well, most likely you have to go for chemo after the surgery." I said, "What do you mean by chemo? It must be cancer... that I have to go on chemo." But then, at that time, she didn't mention the word cancer because it was so scary. [Jennie]

Delays in scheduling tests and learning their results were frustrating for patients awaiting a diagnosis. When the cancer diagnosis was finally forthcoming from the doctor, the patient appreciated being told exactly what the problem was.

...mind you, nobody came. Like, that was on a Thursday morning I had the surgery. Nobody came around Thursday or Thursday night. And I thought, well this doesn't seem right. You know nobody's come and talked to me. ...And my doctor came in the next morning and he said it was a tumour. It wasn't a cyst. And they had me down at (the cancer) hospital within three weeks. [Holly]

They (doctors) were great at coming immediately. Well they told my husband the results I guess before they told me. But I guess I appreciated their honesty, you know, and there was no beating around the bush. Well, they just told me that I had cancer. [Margaret]

Oncology health professionals sometimes presented the initial diagnosis and related information in a candid, understandable, and compassionate manner. Yet, some of the participants appreciated hearing the information in stages. This prevented them from being overwhelmed emotionally by the surprising news and facts about their health.

So when I got to the cancer agency my oncologist was, she was very matter of fact. She didn't give me a lot of information about treatment at that point because she didn't have all the information herself. So she didn't want to talk about, you know, will I lose my hair; what kind of chemo will I get; will I even have chemo? She didn't tell me anything about prognosis. ...I remember being very, very impressed with her manner, with all the people there, all the nursing staff, everyone was just very wonderful. [Pam]

The language used by health professionals was sometimes confusing and not familiar to patients and their family members. Patients were left to assume and interpret the medical jargon on their own. Participants wondered if the health professionals actually knew the answers to their questions or were avoiding issues patients raised.

Well, at the outset, my family physician said, "It's carcinoma and it's metastasized." And my husband said, "What does that mean?" So in retrospect, and I understood her, she could have used lay person's terms. You know, she could have said, "It's cancer and it's spread to whatever area." ...the information wasn't tailored to me or shaped to normal human beings. [Susan]

When I was first diagnosed, a lot of the answers to my questions were "I don't know," from the medical profession. ...At one point I didn't even know if it was really ovarian. I don't know if we don't hear when we have cancer or they don't actually explain it very well. At one time I thought it was cancer of the peritoneum because it had metastasized to the peritoneum. ...But at that time I wasn't as knowledgeable as I am today ...There was a lot of unsureness I thought in terms of the doctors. And it was a very frustrating... when I was first diagnosed I went and got a second opinion and I was getting a similar response. An "I don't know response... we're not sure." [Mary]

\section{Discussion}

This article presents the perspectives of women living with ovarian cancer regarding the peridiagnostic period. The peridiagnostic period is an important one to investigate, given the evidence that early detection decreases mortality for most cancers (Wikborn, Pettersson, \& Moberg, 1996). The open-ended interviews in this study allowed the women to share their perspectives surrounding the recognition, identification, and investigation of symptoms prior to learning they had ovarian cancer. The findings provide insight regarding delay in diagnosis of ovarian cancer that has implications for practice.

Factors associated with diagnostic delay have been described by various investigators, often classifying them as patient factors, physician factors, and health care system factors (Diagnosis Working Group, 2000). Patient delay involves the time it takes a patient to seek help once a symptom has been discovered, while physician and system delay involve the time it takes for a patient to be evaluated, diagnosed, and treated once help has been sought (Caplan \& Helzlsouer, 1992). Furthermore, patient delay has been conceptualized as including an appraisal delay (process of symptom interpretation), illness delay (time between a person concluding he or she is ill and deciding to seek medical help), behavioral delay (time between making a decision to seek help and making an appointment), and scheduling delay (time between making the appointment and receiving the medical attention) (Andersen, Cacioppo, \& Roberts, 1995).

Studies about the reasons for diagnostic delay have reported large variations in the proportion of the delays that are attributed to the patient. For example, in recent work with breast cancer patients, the delay was attributed by the woman herself to the patient in about $25 \%$ of the cases (Caplan, Helzlsouer, Shapiro, Wesley, \& Edwards. 1996). The most common reason given was that the women felt the problem was not important. In about $45 \%$ of the cases, the provider and the health care system were said to be responsible for the delay through difficulties in scheduling or physician inaction. Studies of esophagogastric cancer revealed estimates that patients accounted for $29 \%$ to $80 \%$ of the delays (Martin, Young, Sue-Ling, \& Johnston, 1997; Schmidt, 1997). Lack of knowledge on the patient's part was cited most frequently as the reason for the delays. A similar picture is painted with the findings of this present study. Women spoke about their lack of knowledge regarding the symptoms they were experiencing and having no idea the symptoms could herald cancer. Not realizing their importance, women did not take action immediately upon noticing changes.

The situation with ovarian cancer is also compounded in that the symptoms are rather vague and mimic other gastric disorders, some of which are self-limiting and not lifethreatening. Deciding to seek medical advice can be a complex decision in light of such an uncertain situation. According to Carter and Winslet (1998), there are many reasons why a patient may not actually call a physician: the symptom is not deemed serious enough, it is too unpleasant or embarrassing, a wait-and-see policy is adopted, investigation is feared, the cause is already known, a serious underlying condition is suspected, there may be an association with a dietary indiscretion, a lack of faith in physicians, or a lack of time to consult a physician. According to Hackett and his colleagues (Hackett, Cassem, \& Raker, 1973), what eventually sent patients to seek medical assistance was pain, incapacity, fear, advice from a friend or relative, or attending a routine medical check-up. For the women in this present study, many adopted a wait-and-see approach. They perceived their symptoms as the result of ageing, menopause, or eating something that did not 
agree with them. In retrospect, many reported they would have acted sooner if they had realized the potential seriousness of the symptoms.

Andersen and her colleagues have developed a conceptual model to explain patient delay (Andersen et al., 1995). Their research supports the hypothesis that the appraisal of symptoms or the interpretation of their importance accounts for the major portion of patient delay. Designing interventions aimed at shortening this delay needs to begin by understanding the patients' perceptions during the appraisal process. This current study lends support to that conceptual model. The women with ovarian cancer were aware of their symptoms, but did not assign enough importance to them to seek help immediately. Furthermore, when they did mention the symptoms to their physicians, they tended not to receive feedback initially that would have significantly changed their perceptions.

Once the women in this study realized that the symptoms were not resolving or were becoming more bothersome, they did seek medical advice. The subsequent process of symptom assessment was perceived as long, winding, and fraught with frustration and increasing concern about their health. Responses from the medical community seemed vague and unconcerned. Such descriptions have been reported in other studies, especially where cancer was suspected. The interval of waiting for a diagnostic test result is perceived by individuals as endless, anxiety-provoking, and filled with uncertainty and a pervasive sense of helplessness (Benedict, Williams, \& Baron, 1994; DeGrasse, Hugo, \& Plotnikokk, 1997; Fitch et al., 2000; Northouse, Jeffs, Cracchiolo-Caraway, Lampman, \& Dorris, 1995; Risberg, Sorbye, Norum \& Wist, 1996). It is a time of heightened psychosocial distress (Benedict et al.; Jones \& Greenwood, 1994) which is increasingly aggravated the longer the period of delay (Risberg et al.). Receiving a definitive diagnosis at least places the individual in a position of knowing what has to be faced.

The women in this study described symptoms that are typical of the clinical presentation of ovarian cancer (Goff, Mandel, Muntz, \& Melancon, 2000). These symptoms do mimic common inflammatory gastrointestinal disease, despite the reality that the symptoms could also herald widespread ovarian cancer. This makes diagnosis of ovarian cancer a complex clinical process (Wikborn et al., 1996). The standard process of differential diagnosis supports the approach of ruling out the most common explanation for the symptoms as an initial step. However, as these women reflected back upon the process of being investigated, they expressed dismay at the length of time they felt it took physicians to focus on ovarian cancer as a possible explanation for their symptoms. They felt time had been lost with pursuit of other needless investigations.

Physician and system delay in diagnosis are increasingly of concern in our health care system. Goff et al. (2000) reported factors that were significantly associated with delay in diagnosis of ovarian cancer included omission of pelvic examination on the first visit; having a multitude of symptoms; being diagnosed initially as having no problem, depression, stress, irritable bowel, or gastritis; not initially receiving ultrasound, computed tomography, or CA-125 test; and younger age. Additionally, a recent survey of Canadian family physicians revealed considerable variation in their knowledge of the risk factors for ovarian cancer (Gray et al., 1999).

Of particular concern, however, is the women's perspectives that they were not heard when they voiced their fears or shared their symptoms. They perceived their concerns were dismissed. This type of communication added frustration to a situation already filled with uncertainty. Many felt they had to be more than assertive to have their concerns addressed. They harboured an inner conviction that something was wrong with their body, yet they received little support for that conviction from health care professionals. This type of interaction can easily undermine a relationship between a patient and health care professional.

At the time of the interview, the women in this study still carried a sense of anger about the communication process between themselves and the physicians involved in the peridiagnostic period. The perspectives about communication shared by the women in this study raise questions about the skills health care professionals have in being sensitive and responsive to patients' needs in the midst of increasing patient loads and decreasing resources in clinical settings. Similar communication issues have also been reported by breast cancer patients and led to the development of special communication programs (Parboosingh \& Inhaber, 1998). Creative solutions are also needed to overcome this communication barrier for ovarian cancer patients during the peridiagnostic period.

\section{Implications for education, research and practice}

The findings from this study have implications, firstly, for public education. Given that so many women did not have an awareness about the risk factors and symptoms of ovarian cancer, there could be benefit from the development of public education materials to inform women about these matters. There is also a clear need for the development of better screening tests for the identification of ovarian cancer at an early stage. Having a definitive test could preclude the seemingly lengthy process of symptom assessment women currently undergo.

In terms of nursing practice, implications arise from this study in several areas. Firstly, nurses need to be aware of the risk factors and symptoms of ovarian cancer and share that information with their female patients. Nurses who work in community health settings and physician offices are in ideal positions for such education with well women. Nurses in any setting who are aware their patients have potential risk factors for ovarian cancer may wish to have a focused discussion about it with those women. The discussion could focus on being aware of bodily changes, interpreting the importance of those changes, and taking appropriate action.

Secondly, nurses need to pay particular attention to the descriptions of any changes a woman is experiencing, particularly bloating, weight gain around her stomach, alterations in bowel or bladder function, indigestion, or pelvic pain. Nurses could play a role in supporting the woman and helping her interpret the importance of the symptoms. While the woman is undergoing investigation, nurses could help her understand and prepare for test procedures, and set expectations for what will be learned from the test results and when the results will be available. Nurses can be advocates for scheduling tests and reporting findings in a timely manner. Recognizing that the peridiagnostic period is a time of high stress, nurses need to be assessing when an individual could benefit from referral to counselling. Ensuring women have contact information for relevant agencies where women could obtain information would also be important. Particularly for ovarian cancer, the Cancer Information Services (1-888-939-3333) and the National Ovarian Cancer Association (1-877-413-7970) could be valuable resources.

Finally, in terms of communication, nurses have a role to play in fostering therapeutic exchange. Nurses need to be aware of how patients are perceiving the behaviours of health care professionals and whether the women feel the professionals are hearing and attending to their voiced concerns. Patients may need to learn about the health care system and the process for making a diagnosis so they can understand what is happening to them, why they are undergoing the specific diagnostic procedures, and what kind of timelines to expect. In particular, the nurse caring for the woman at the time she learns of her diagnosis needs to be aware of the impact of that diagnosis and be sensitive to that individual's perspective. Even though a definitive diagnosis may herald the end of uncertainty about what is wrong, it marks the beginning of the uncertainty about treatment and its impact.
CONJ • 12/3/02
RCSIO • 12/3/02 


\section{References}

Allchin-Petardi, L. (1998). Weathering the storm: Persevering through a difficult time. Nursing Science Quarterly, 11(4), 1727.

Andersen, B.L., Cacioppo, J.T., \& Roberts, D.C. (1995). Delay in seeking a cancer diagnosis: Delay stages and psychophysiology comparison processes. British Journal of Social Psychology, 34, 33-52.

Balat, O., Kudelka, A.P., Tunca, J.C., Edwards, C.L., Verschraegen, C., \& Kavanaugh, J.J. (1996). Prolonged stabilization of progressive platinum-refractory ovarian cancer with paclitaxil: Brief report. European Journal of Gynaecological Oncology, 18(4), 264-266.

Benedict, S., Williams, R.D., \& Baron, P.L. (1994). Recalled anxiety: From discovery to diagnosis of a benign breast mass. Oncology Nursing Forum, 21(10), 1723-7.

Cain, E.N., Kohorn, E.I., Quinlan, D.M., Schwartz, P.E., Latimer, K., \& Rogers, L. (1983). Psychosocial reactions to the diagnosis of gynecologic cancer. Obstetrics \& Gynaecology, 62(5), 635-641.

Caplan, L.S., \& Helzlsourer, K.J. (1992/93). Delay in breast cancer: A review of the literature. Public Health Review, 20, 187-214.

Caplan, L.S., Helzlsouer, K.J., Shapiro, S., Wesley, M.N., \& Edwards, B.K. (1996). Reasons for delay in breast cancer diagnosis. Preventative Medicine, 25(2), 218-24.

Carter, S., \& Winslet, M. (1998). Delay in the presentation of colorectal carcinoma: A review of causation. International Journal of Colorectal Diseases, 13, 27-31.

Clark, A.J., \& Matassarin, E. (1993). Nursing care of women with gynecologic disorders. In J.M. Black \& E. Matassarin-Jacobs (Eds.), Medical-surgical nursing: A psychophysiologic approach $\left(4^{\text {th }} \mathrm{ed}\right.$., pp. 2145-2146). Chicago: W.B. Saunders Company.

Dawson, T. (1993). Ovarian cancer: The experiences of women after treatment. Journal of Cancer Care, 2(1), 39-44.

DeGrasse, C.E., Hugo, K., \& Plotnikokk, R.C. (1997, October). Supporting women during breast diagnostics. Canadian Nurse, 24-30.

Diagnosis Working Group. (2000). Report of the Diagnosis Working Group, Canadian Cancer Control Strategy. Ottawa, ON: Health Canada.

Ersek, M., Ferrell, B.R., Dow, K.H., \& Melancon, C.H. (1997). Quality of life in women with ovarian cancer. Western Journal of Nursing Research, 19(3), 334-350.

Fitch, M.I., Gray, R.E., DePetrillo, D., Franssen, E., \& Howell, D. (1999). Canadian women's perspectives on ovarian cancer. Cancer Prevention and Control, 3(1), 52-60.

Fitch, M.I., Gray, R.E., McGowan, T., Brunskill, I., Steggles, S., Sellick, S., Bezjak, A., \& McLeese, D. (2000). Evaluation report of the radiation re-referral program for Cancer Care Ontario. Toronto, ON: Cancer Care Ontario.

Goff, B.A., Mandel, L., Muntz, H.G., \& Melancon, C.H. (2000). Ovarian carcinoma diagnosis. Cancer, 89(10), 2068-75.

Gray, R.E., Chart, P., Carroll, J.C., Fitch, M.I., \& Cloutier-Fisher, D. (1999). Family physician perspectives on ovarian cancer. Cancer Prevention and Control, 3(1), 61-67.

Gray, R.E., Fitch, M., Greenberg, M., Hampson, A., Doherty, M., \& Labrecque, M. (1998). The information needs of well, long-term survivors of breast cancer. Patient Education and Counselling, 33, 245-255.

Gray, R.E., Greenberg, M., Fitch, M., Sawka, C., Hampson, A., Lebrecque, M., \& Moore, B. (1998). Information needs of women with metastatic breast cancer. Cancer Prevention and Control, 2(2), 57-62.

Guidozzi, F. (1993). Living with ovarian cancer. Gynaecologic Oncology, 55, 202-207.
Hackett, T., Cassem, N., \& Raker, T. (1973). Patient delay in cancer. New England Medical Journal, 289, 14-20.

Health Canada. (1999). Ovarian cancer in Canada: A background document. Ottawa, ON: Health Canada, Health Protection Branch, Cancer Control Assessment and Surveillance Division, Cancer Bureau, Laboratory Centre for Disease Control

Jones, R.V., \& Greenwood, B. (1994). Breast cancer: Causes of patients' distress identified by qualitative analysis. British Journal of General Practice, 44, 370-371.

Kornblith, A.B., Thaler, H.T., Wong, G., Vlamis, V., Lepore, J.M., Loseth, D., Hakes, T., Hoskins, W.J., \& Portenoy, R.K. (1995). Quality of life of women with ovarian cancer. Gynaecological Oncology, 59, 231-342.

Lee, C.O. (2000). Gynecologic cancers: Part I - risk factors. Clinical Journal of Oncology Nursing, 4(2), 67-71.

Martin, I.G., Young, S., Sue-ling, H., \& Johnston, D. (1997). Delays in the diagnosis of oesophagogastric cancer: A consecutive case series. British Medical Journal, 314, 467-71.

Montazeri, A., McEwen, J., \& Gillis, C.R. (1996). Quality of life with ovarian cancer: Current state of research. Supportive Cancer Care, 4, 169-179.

National Cancer Institute of Canada. [NCIC]. 2000. Canadian cancer statistics. Toronto, $\mathrm{ON}$ : Author.

Northouse, L.L., Jeffs, M., Cracchiolo-Caraway, A., Lampman, L., \& Dorris, G. (1995). Emotional distress reported by women and husbands prior to a breast biopsy. Nursing Research, 44, 196-201.

Parboosingh, J., \& Inhaber, S. (1998). A catalyst for change in communication skills: The Canadian Breast Cancer Initiative. Cancer Prevention and Control, 3(1), 19-24.

Payne, S.A. (1990). Coping with palliative chemotherapy. Journal of Advanced Nursing, 15(6), 652-8.

Portenoy, R.K., Kornblith, A.B., Wong, G., Vlamis, Y., Lepore, J.M., Loseth, D.B., Hakes, T., Foley, K.M., \& Hoskins, W.J. (1994). Pain in ovarian cancer: Prevalence, characteristics and associated symptoms. Cancer, 74(3), 907-15.

Portenoy, R.K., Thaler, H.T., Kornblith, A.B., Lepore, J.M., Friedlander-Klar, H., Coyle, N., Smart-Curley, T., Kemeny, N., Norton, L., Hoskins, W., \& Scher, H. (1994). Symptom prevalence, characteristics and distress in a cancer population. Quality of Life Research, 3, 183-189.

Powel, L. (1998). A pilot study describing the demands of illness for women with ovarian cancer. Oncology Nursing Forum, 25(2), 353.

Risberg, T., Sorbye, S.W., Norum, J., \& Wist, E.A. (1996). Diagnostic delay causes more psychological distress in female than in male cancer patients. Anticancer Research, 16(2), 995-9.

Roberts, C.S., Rossetti, K., Cone, D., \& Cavanagh, D. (1992) Psychosocial impact of gynaecological cancer: A descriptive study. Journal of Psycho-oncology, 10(1), 99-109.

Schmidt, J.G. (1997). Delays in diagnosing oesophagogastric cancer. British Medical Journal, 315, 426-427.

Thompson, S.D., Szukiewicz-Nugeng, J.M., \& Walczak, J.R. (1996). When ovarian cancer strikes. Cancer Nursing, 26(10), 33-8.

Wikborn, C., Pettersson, F., \& Moberg, P.J. (1996). Delay in diagnosis of epithelial ovarian cancer. International Journal of Gynaecology and Obstetrics, 52(3),263-7.

Young, R.C. (1995). Ovarian cancer. CA Cancer Journal for Clinicians, 45(2), 69-70.

Zacharias, D.R., Gilag, C.A., \& Foxall, M.J. (1994). Quality of life and coping in patients with gynecologic cancer and their spouses. Oncology Nursing Forum, 21, 1699-1706. 